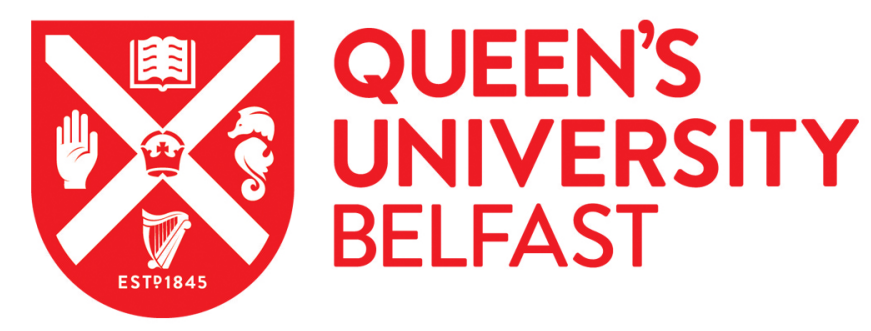

\title{
Techniques for Multiple-Set Synchronous Islanding Control
}

Best, R. J., Morrow, D. J., Laverty, D. M., \& Crossley, P. A. (2011). Techniques for Multiple-Set Synchronous Islanding Control. IEEE Transactions on Smart Grid, 2(1), 60 - 67. https://doi.org/10.1109/TSG.2010.2100833

\author{
Published in: \\ IEEE Transactions on Smart Grid
}

Document Version:

Peer reviewed version

Queen's University Belfast - Research Portal:

Link to publication record in Queen's University Belfast Research Portal

Publisher rights

Copyright 2011, IEEE.

This work is made available online in accordance with the publisher's policies. Please refer to any applicable terms of use of the publisher.

\section{General rights}

Copyright for the publications made accessible via the Queen's University Belfast Research Portal is retained by the author(s) and / or other copyright owners and it is a condition of accessing these publications that users recognise and abide by the legal requirements associated with these rights.

Take down policy

The Research Portal is Queen's institutional repository that provides access to Queen's research output. Every effort has been made to ensure that content in the Research Portal does not infringe any person's rights, or applicable UK laws. If you discover content in the Research Portal that you believe breaches copyright or violates any law, please contact openaccess@qub.ac.uk. 


\title{
Techniques for Multiple-Set Synchronous Islanding Control
}

\author{
R. J. Best, D. J. Morrow, D. M. Laverty and P. A. Crossley
}

\begin{abstract}
Power system islanding can improve the continuity of power supply. Synchronous islanded operation enables the islanded system to remain in phase with the main power system while not electrically connected, so avoiding out-of-synchronism re-closure. Specific consideration is required for the multiple-set scenario. In this paper a suitable island management system is proposed, with the emphasis being on maximum island flexibility by allowing passive islanding transitions to occur, facilitated by intelligent control. These transitions include: island detection, identification, fragmentation, merging and return-to-mains. It can be challenging to detect these transitions while maintaining synchronous islanded operation. The performance of this control system in the presence of a variable wind power in-feed is also examined. A Mathworks SimPowerSystems simulation is used to investigate the performance of the island management system. The benefit and requirements for energy storage, communications and distribution system protection for this application are considered.
\end{abstract}

Index Terms-Distributed generation, frequency control, load sharing, phase control, phasor measurement, power system islanding, power distribution control, synchronization

\section{INTRODUCTION}

$\mathrm{T}^{\mathrm{s}}$ HERE is potential to improve power system security by enabling sections of the distribution network to separate from the main power system and operate autonomously as power system islands. An increasing capacity of Distributed Generation (DG) connected at the distribution level [1], and the incorporation of technological advancement in digital control [2] and modern communications [3, 4] into power system operation, means that many more power system areas are suitable for islanding schemes.

Thus, of late, power system islanding and microgrids have been receiving worldwide interest $[5,6$, 7]. However, for islanding to become widespread the major technological issues of power quality, protection, out-of-synchronism re-closure and earthing must be addressed [1]. Furthermore, new sophisticated methods of control and island management will be re-

This work is funded through the EPSRC Supergen V, UK Energy Infrastructure (AMPerES) grant in collaboration with UK electricity network operators working under Ofgem's Innovation Funding Incentive scheme; full details on http://www.supergen-amperes.org.

R. J. Best, D. J. Morrow, and D. M. Laverty are with the Electrical Power and Energy Research Cluster, Queen's University Belfast, Belfast BT9 5AH, Northern Ireland (e-mail: rbest02@qub.ac.uk; dj.morrow@ee.qub.ac.uk; dlaverty03@qub.ac.uk).

P. A. Crossley is with the Joule Centre, The University of Manchester, Manchester M60 1QD, U.K. (e-mail: p.crossley@manchester.ac.uk). quired to allow the potentially large number of separate islanded areas to operate simultaneously and adjacently.

Ideally, islanding can be used to add flexibility to the operational capabilities of DG and the distribution network. In this paper the authors explore a method to perform islanding control and synchronization of autonomous multi-set distribution system islands, where the island boundary is not necessarily known or clearly defined. The islands may be of arbitrary size, containing varying numbers and types of DG, based on loadgeneration match and other system conditions at the time of islanding.

To achieve this, the concept of synchronous islanded operation is introduced. The objective is to control all the islands to remain in synchronism with each other and the main power system, and is achieved by appropriate control and the transmission of a reference signal from the main power system. This would allow the fast reconnection of islands without the danger of out-of-synchronism re-closure.

Such a system could facilitate the amorphous forming and merging of islands in a manner which minimizes the disruption to customers that may otherwise occur following the opening of a circuit breaker. The island's boundaries may be ill defined and comprehensive knowledge of those circuit breakers that remain closed and those that remain open is not required. In addition, when a number of islands merge, synchronization is provided using measurements remote from the actual point of connection, thus negating the requirement to have synchronization relays at every possible connection point.

The authors have already performed significant work in the single-set scenario, which determined that the governor control system of DG could be used to control phase on an indefinite basis $[8,9]$. The results indicate that with a sophisticated governor and suitable communications structure, this is indeed feasible in the single-set case. Experimental work was also performed to determine suitable boundaries within which to control the phase angle [10]. A range of $\pm 60^{\circ}$ was proposed, this being no worse than a sudden three phase short-circuit, which the DG is designed to withstand, and is a significantly wider window than current synchronization schemes operate with $[11,12]$. It is acknowledged that this may not be acceptable for all DG, and so these limits could be reduced, however, these are intended as maximum limits and the control system will ensure that the normal phase difference is much lower.

However, multiple-set operation is a more likely scenario and several additional challenges have been identified, which are complicated by the tight frequency control requirements of 
synchronous islanding [13]. The challenges considered in this paper are: a multiple-set island management scheme specifically for phase controlled islands; load sharing; suitable multipleset frequency and phase difference control; the effect of substantial renewable generation with variable power output on the control scheme; protection co-ordination; and communication requirements. Enabling technologies for this wide-area scheme will be synchrophasors, Internet communications and supervisory levels of control external to the DG.

\section{ISLAND MANAGEMENT}

Several authors have proposed strategies for identification and splitting of the network into stable and maintainable islands, largely relying on prior knowledge of the system's status. Examples are splitting based on closely matched load and generation $[14,15]$, generators that tend to swing together or slow coherency [16], predefined cells [6], and inverter dominated and highly automated microgrids $[5,17,18]$.

In this paper the authors propose an islanding management strategy that could work in conjunction with these methods, but can also give islands that have not been pre-defined the best chance to continue operation. Additionally, the strategy is compatible with the idea of controlling phase difference of all islands to be in synchronism with the main power system, and thus each other.

An island management scheme, in addition to providing stable steady-state control, must also be able to detect and cope with the various transitions and reconfigurations that may occur during islanding. These are as follows: island detection and identification, island fragmentation or DG loss, return-tomains detection, island merging, and island shut-down [19]. These islanding state transitions are shown in Fig. 1.

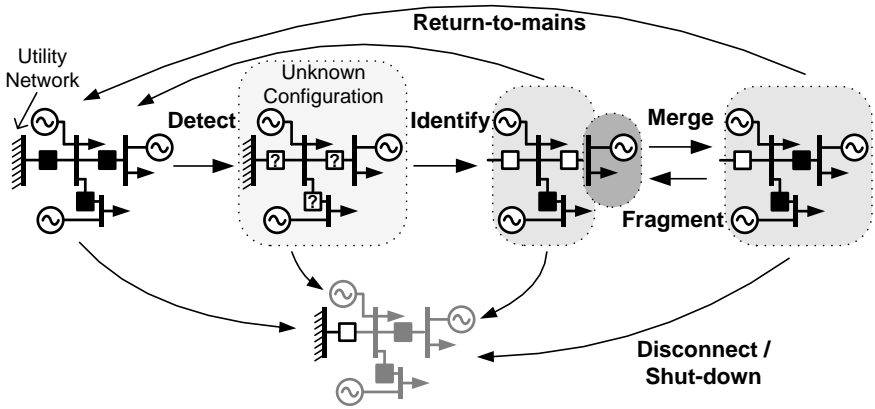

Fig. 1. Islanding state transitions

The proposal is that not all island reconfigurations will occur 'actively' with prior-knowledge of the system operator, or will be executed by the utility's control system. One example is the mal-operation of protection. Thus a suitable monitoring and control scheme is required which can act 'passively' as well as 'actively'. The aim is, where possible, to use algorithms which operate locally at the DG, for speed and reliability. However, a supervisory controller will provide a communication link between all DG to ensure stability, continuous operation and correct performance of certain operations. Such a structure encompassing local control at the DG (primary) and supervisory wide-area control (secondary) is shown in Fig. 2.
The control system must be tolerant to telecommunication delay and be robust to temporary communication outages. Furthermore, it is envisaged that Internet Protocol (IP) communication will be used, as this would provide a low cost and feasible solution for the distribution network. Time-stamped phasor measurements [20] will play an important role in the operation of a multiple-set synchronous island.

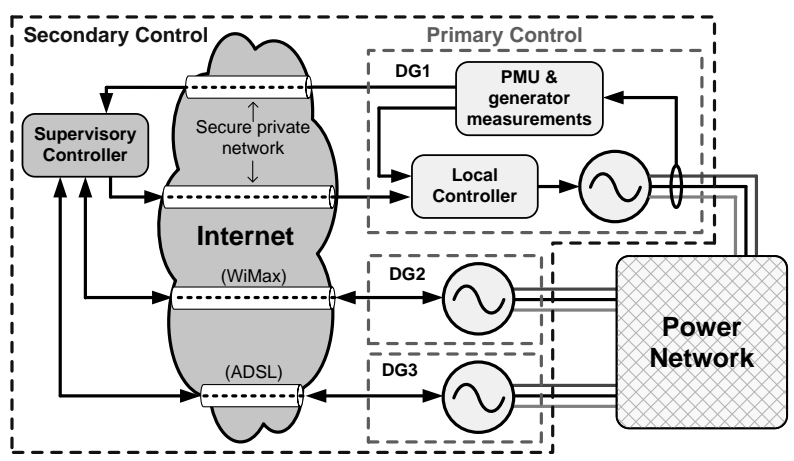

Fig. 2. Local and supervisory control levels for multiple-set islanding

\section{A. Island Identification}

It is proposed that island detection be performed locally at each DG for maximum speed of operation. On the detection of islanding, each DG initially assumes it is in single-set operation and changes its control function accordingly. Island detection may be performed using synchrophasor measurements [21], as the reference signal from the main power system is available for phase difference control during synchronous islanded operation.

This scenario of assumed single-set operation cannot be maintained indefinitely in the multiple-set case. This is because the control systems will conflict with those of other DG if they are not coordinated, leading to, for example, hunting or integrator windup. So it is a requirement of the supervisory controller to identify which DG are in each island, and initiate an appropriate coordinated control strategy, load sharing, etc.

It is proposed that voltage phase angle be used to identify DG in the same island, or 'island membership', by comparing phasor measurements at the supervisory controller. Once the island is identified, steady-state control functions, such as real power load sharing, can begin.

\section{B. Island Fragmentation and Distributed Generator Loss}

The island may fragment into smaller islands, or a DG may be lost from the island. Continued operation will require a reconfiguration of the control system. The supervisory controller must ensure that all DG perform full frequency and phase control as required, and that load sharing between the separated DG is suspended. The supervisory controller can detect island fragmentation by monitoring the voltage phase angle between each generator. 
DG loss, and in many cases the act of island fragmentation, will cause a frequency transient and phase deviation. Synchronous islanded operation can only continue if this load imbalance, or any other load disturbance, does not cause the $\pm 60^{\circ}$ limit to be exceeded. The phase deviation is also influenced by the DG speed of response and the system inertia.

\section{Return-to-Mains and Island Merging}

It is necessary to know when return-to-mains or island merging has occurred in order to change DG control modes and ensure stable operation. However, it is difficult to detect return-to-mains or island merging when each islanded power network is held in phase with the main system. This is because only minimal power system transient is observed. Since returnto-mains detection is not as critical as other functions, and can be performed on a timescale of tens of seconds, there are a number of possible solutions. These include: knowledge of all circuit breaker status; islanding detection techniques not based on frequency or phase deviation; power line carrier signals; controller limits being reached when the DG attempts to control the infinite bus, assuming a decision is made before protection operates; and power perturbations by the islanded DG, which may reduce power quality.

A further method is proposed; based on the assumption that the grid connected phase difference is more stable than the islanded system phase difference. The variance of the phase difference is calculated from a set of phasor measurements taken over a specified period of time [19]. For example, 2 or 3 seconds of phasor measurements sampled at $25 \mathrm{~Hz}$ would be suitable. A low variance can be considered equivalent to electrical connection. If the variance remains below a certain threshold for a number of calculations, then return-to-mains is assumed to have occurred and an appropriate controller reconfiguration can be activated. Thus, the return-to-mains detection would operate on a timescale of $5-10$ seconds which, as previously stated, is acceptable. The phase difference must be prefiltered if noise and erroneous values are not to affect the operation of this function. Laboratory results for this technique are given in [19].

Island merging can be detected by monitoring the variance of the voltage phase angle between individual DG, and would be performed at the central supervisory controller. Again, a low variance between the phasor measurements of different DG would be equivalent to electrical connection.

A flow chart for the island management scheme and controller selection is shown in Fig. 3.

\section{ISLAND CONTROL}

As there may be considerable distance between DG, a suitable supervisory control system is proposed that could operate effectively using IP communications and relatively slow information update rates, of the order of several seconds.

\section{A. Multiple-Set Control}

In a multiple-set isochronous frequency or phase controlled island, using a single set to perform the master control is easier to implement than a multiple-set control option, and does not, to the same extent, rely upon communications, adequate controller design and careful tuning.

However, multiple-set control has some advantages: more control options are available, all DG in the island can respond to disturbances as one set or in the most appropriate manner, following a disturbance all generators respond to control phase difference, and following the loss of a generator there will be a faster return to stable synchronous islanded operation.

In schemes with many DG performing primary proportional, integral, derivative (PID) control functions, measurement errors can cause the control systems of each generator to conflict. The solution is an accurate measurement of variables combined with communications between sets. Typically this is available for DG in close proximity to one another, in the same building for example [22]. A similar scheme could be applied using modern communications methods, and a secondary control loop as in Fig. 2 to facilitate multiple-set phase difference control and load sharing.

The controller used at each DG is shown in Fig. 4. The phase and frequency references are taken from the reference power system, a location on the main network, which may be used to allow synchronous operation of several adjacent islands. Data are collated from all DG at the supervisory controller before the load set-point for each DG is calculated and transmitted periodically to the DG. Thus, as well as permitting load sharing, this set-point can prevent control errors causing wind-up in the integral functions of the DG governors.

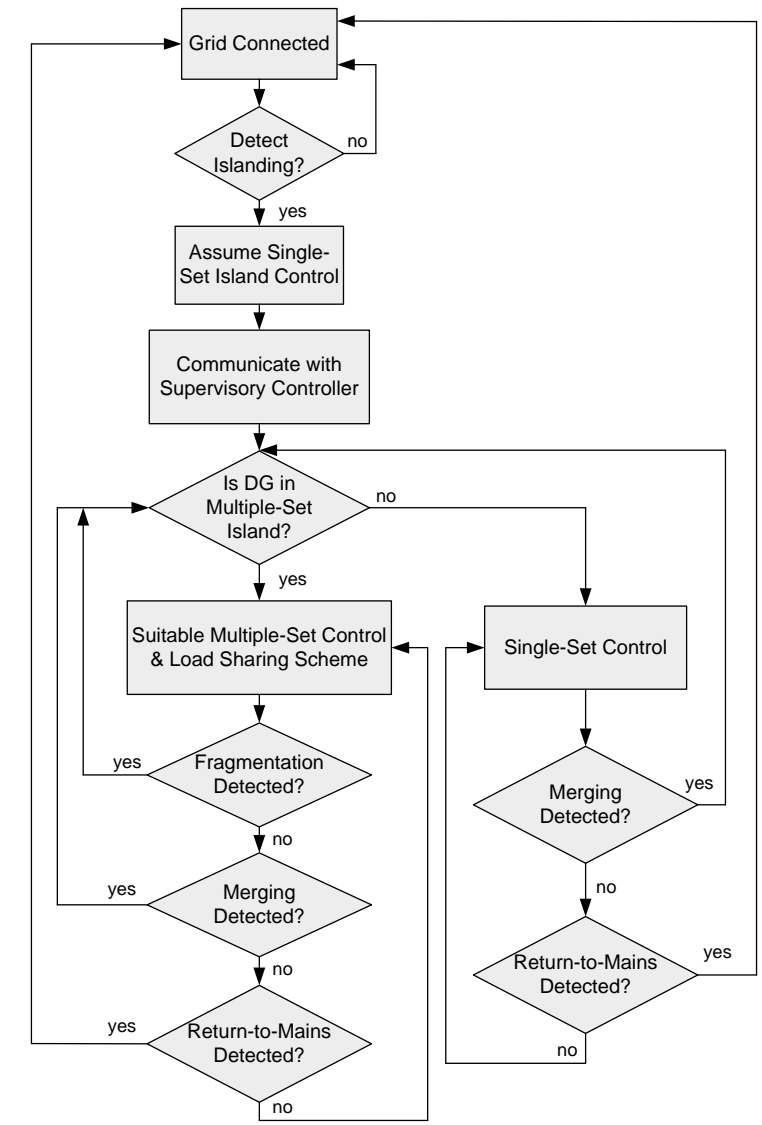

Fig. 3. Flow chart for island management and controller selection 


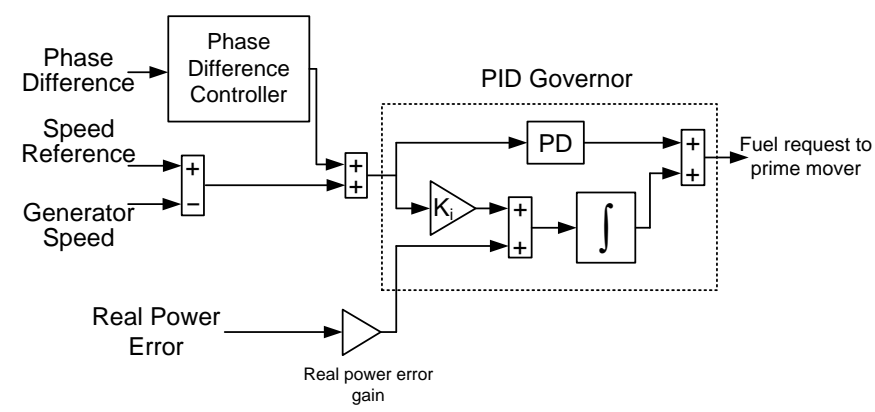

Fig. 4. DG frequency, phase difference and load sharing controller

An enhanced governor with additional control inputs can be used to improve the response. It was shown in [8] that a governor with supplementary inputs [23] could significantly improve the phase control by reducing the frequency deviation.

The inertia from DG not involved in phase difference control, while beneficially reducing frequency deviation during load disturbances, can actually slow the recovery and increase the maximum phase difference.

\section{B. Load Sharing}

For an island to maintain satisfactory operation it is convenient that load is shared either equally or following some other strategy, among the DG. Frequency droop is the well established method typically employed for real power load sharing between multiple DG within an island, and others have proposed its use for load sharing in multiple-set microgrids $[18,24]$. This method uses frequency to 'communicate' load settings between DG. However, it is often desirable to control frequency to a nominal value, that is, isochronous frequency control. Isochronous operation of multiple DG requires communication or some form of hard wiring [22]. In the case of synchronous islanded operation, a frequency set-point is a prerequisite and so droop for load sharing is not an option. Thus, and because DG may be some distance apart, a control strategy that provides load sharing via communications is required [13].

From a system stability perspective, the load-frequency control set-point should not be updated too frequently, typically 2-4 seconds [25]. This allows sufficient time to acquire data from the system, make a decision and send the information back to the generators.

An additional difficulty for synchronous islanded operation is that changing the generators' real power set-points can introduce a frequency disturbance and thus increase phase deviation. This problem can be relieved by introducing a rate-limit for any real power set-point adjustments. When the generator is controlled by a Proportional, Derivative (PD) phase difference controller and PID governor [13], as can be represented by Fig. 4, a ramp of power output will introduce a steady-state phase difference error during the time of ramping. Thus a balance must be achieved between the desired rate-of-change of power and the acceptable steady-state phase difference error. Thus, as shown in Fig. 4 the load sharing input has a low gain and only feeds into the integral input of the governor.
While in this case it is acceptable to share voltage and reactive power by using voltage droop, it would be beneficial to use a similar communications based scheme.

\section{SimULATION}

To illustrate how an island management scheme might be expected to operate, a model of a distribution system has been constructed in Mathworks SimPowerSystems, shown in Fig. 5. This $11 \mathrm{kV}$ distribution network has three types of DG: a 2 MVA diesel generator, a 4.5 MVA gas turbine, and a 2.5 MW fixed-speed wind farm consisting of several coherent induction machines and 0.75 MVAr at fixed capacitance for reactive power support. Only the diesel generator and gas turbine participate in the synchronous island control. They are capable of island control functions, such as real power load sharing and phase difference control, as discussed in Section III. Reactive power is shared between them using a voltage droop based load compensation method, since it is sufficient to maintain voltage within statutory limits during synchronous islanded operation. This could be upgraded in future implementations due to the presence of communications. The wind farm has been added to create a realistic, but more difficult, scenario for the phase controller. Power output data from an actual wind farm has been used, thus giving the simulation the benefit of a real-world variation in wind power output. The variable wind power output means that the other DG in the island must continuously adjust their power outputs to control phase. The load, totaling 4.5 MW, is distributed along the feeder and is modeled as constant impedance static load.

Parameters for the components of the simulation model are provided in the appendix.

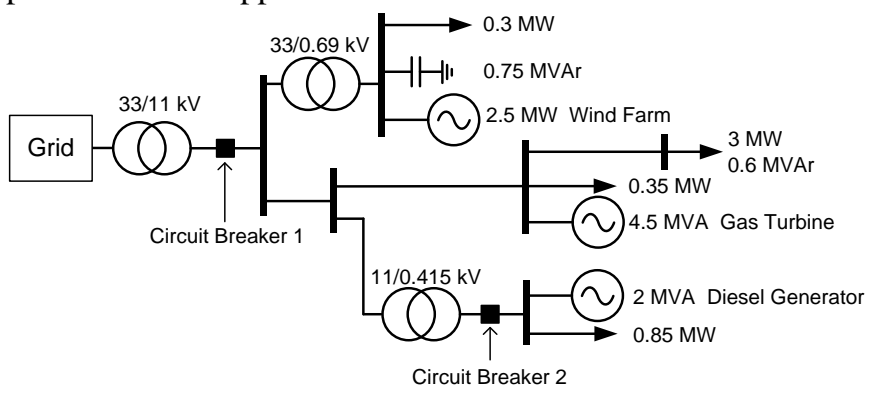

Fig. 5. Diagram of simulated network

\section{A. Island Management System}

Island management for each DG follows the flow chart in Fig. 3. Detection of islanding is performed locally, while island identification, fragmentation and merging detection are performed by the supervisory controller. Return-to-mains can be performed locally, but communication with the supervisory controller is preferable.

The presence of the wind farm is also identified by the supervisory controller, although it is not involved in the control of this island. Identification of all DG and major rotating loads would allow system inertia to be estimated, and could form the basis for having adaptive governor gains in reconfigurable islands. 


\section{B. Simulation Results}

The simulation shows how the island transfers through the different states. Islanding is initiated by the opening of Circuit Breaker 1 in Fig. 5 at $t=30 \mathrm{~s}$. Fig. 6 shows frequency, phase difference and real power during the process of island formation, detection and identification. Satisfactory steady-state synchronous islanding control is achieved within 4 seconds, although equal load sharing takes longer to occur. The formation transient suggests a minimum setting for automatic recloser delays of at least 10 seconds should be used [26]. Load sharing is performed slowly in this control system to reduce the associated phase error, observed in Fig. 6 as a negative phase offset from $t=36 \mathrm{~s}$ onwards.

Fragmentation and merging are initiated by the opening and closing of Circuit Breaker 2 in Fig. 5 at $t=55 \mathrm{~s}$ and $t=80 \mathrm{~s}$ respectively. Circuit Breaker 1 closes at $t=110 \mathrm{~s}$, causing the island to return-to-mains. Fig. 7 shows the phase difference and real power during island fragmentation, merging and return-to-mains transitions. With the load imbalance caused by island fragmentation of $160 \mathrm{~kW}$ it is possible to maintain phase difference within the $\pm 60^{\circ}$ limits. Following larger load imbalances caused by fragmentation or DG loss, synchronous islanding can only continue if it can be assured that open circuit breakers will not close until stability is achieved.
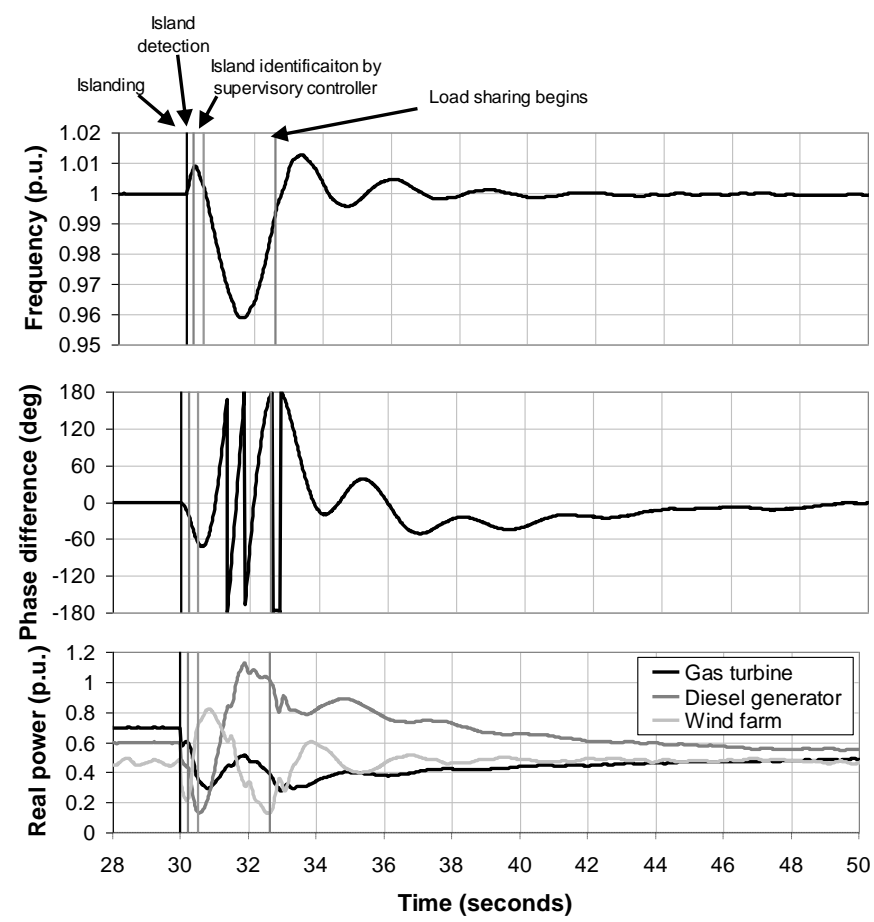

Fig. 6. Island formation, detection and identification

Return-to-mains and merging detection using the voltage phase variance method works well in the presence of varying load, or when the wind farm is in the island. During the time when the diesel generator is isolated and subject to constant load, there is no phase variance as observed in Fig. 7 from $t=65 \mathrm{~s}$ to $t=80 \mathrm{~s}$. This may cause the management system to misidentify return-to-mains. In the simulation correct operation of these functions is only achieved by the periodic switching of a small load $(0.25 \%$ of the generation capacity in the 'diesel' island). However, return-to-mains and merging detection should be easier to apply in practice due to noise and measurement errors causing small variations in controller output and thus alternator speed [19].
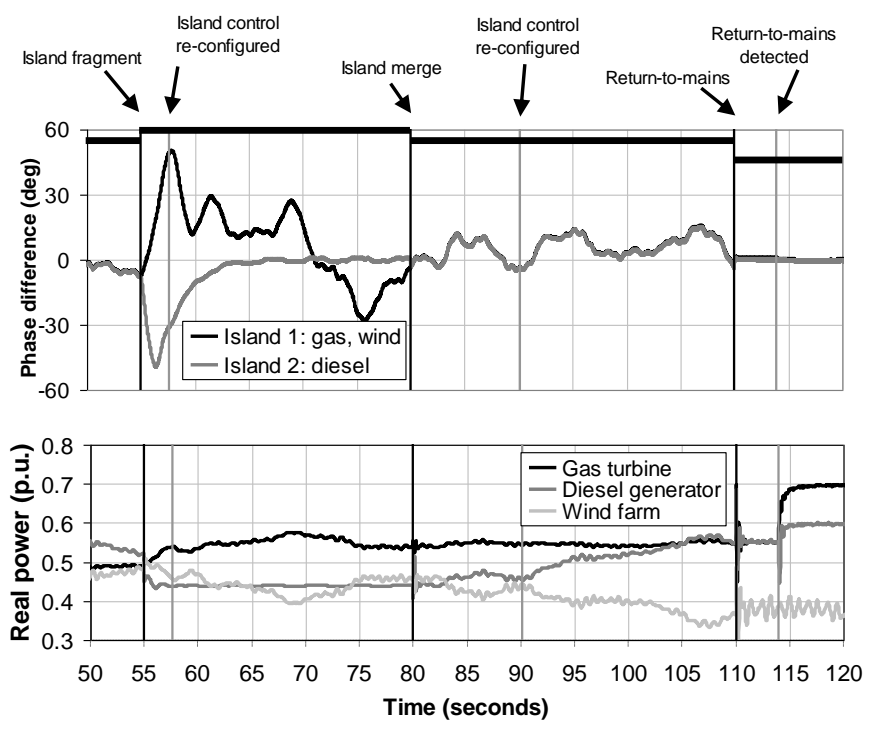

Fig. 7. Island fragmentation, merging and return-to-mains

\section{AdDITIONAL CONSIDERATIONS}

\section{A. Control with Significant In-Feed from Renewables}

The implication of high capacities of renewable resources on the ability of islands to keep within frequency and voltage limits must be considered. From the perspective of phase control, the difficulty is attributable to the variable and limited controllability of the power output from renewables such as wind turbines.

In the current simulation studies the real power output of the renewable source is derived from actual measurements taken from a $2.5 \mathrm{MW}$ wind farm, thus giving the synchronous island a realistic wind power variation. The wind power output data used in the simulation ranges from $34 \%$ to $60 \%$ of the installed capacity. It is documented by Lundsager et al [27] that isolated wind-diesel systems of this size $(\approx 5 \mathrm{MW})$, with normal frequency variation allowances, might currently sustain an average wind energy penetration of $25 \%-35 \%$, rising to $60 \%$ or more in the future.

Frequency variation is particularly restricted for synchronous islanded operation, and the result is that higher penetrations of wind energy may be a hindrance to phase control, particularly for fixed-speed induction machines. In this case study the short-term power variation associated with an average wind penetration of approximately $24 \%$ can be comfortably balanced. In Fig. 7, after the island fragmentation transient, from $t=60 \mathrm{~s}$ to $t=80 \mathrm{~s}$, the 'gas-wind' island can be held within $\pm 30^{\circ}$. When island merging occurs with the faster responding diesel engine $t=80 \mathrm{~s}$, control is improved and phase can be kept to around $\pm 15^{\circ}$. Thus it is observed that faster responding generation is beneficial in this type of island.

The solution to this control issue would be to combine the advanced control strategy introduced in the previous section 
with renewable energy technologies better suited to aiding control response. One example is to replace induction machines with Doubly Fed Induction Generators (DFIG) to reduce short term variability and provide additional control capability $[28,29,30]$. The benefit obtained from DFIG is due to the fast response of the storage in the converter. It follows that fast acting energy storage would be ideal for phase control.

Energy storage for medium term intermittence of renewables (minutes to hours) is an integral part of many microgrid systems [5]. Fast acting energy storage, such as battery or flywheel, and a suitable energy storage control system that can balance or smooth short term load-generation mismatches quickly (second or sub-second) would significantly increase the in-feed from renewables possible in a phase controlled system.

There are occasions, however, where either curtailment of renewable in-feed or load management would be necessary to ensure a load-generation match and to provide the required frequency stability in the island for phase control.

\section{B. Island Protection}

Power system islanding will involve significant grid reconfiguration, especially if maximum flexibility of operation is to be attained.

Conventional overcurrent protection will be unsuitable due to lower fault current from DG. Other techniques, such as voltage-restrained directional overcurrent [31] could be used to detect faults, and Permanent Magnet Generators (PMG) may be required on synchronous machine interfaced DG to supply fault current. However, protection selectivity will be an issue due to the gentle voltage gradients that will be observed in islands, and when fault paths change due to reconfiguration. Islanded distribution networks will require a protection system which is dynamic and adaptable with the facility to cope with network reconfigurations and DG connections and disconnections. It is difficult to envisage protection in islanding capable networks without communications.

As reliable communications will be a prerequisite for stable islanding, it can also be used for protection. In [32] the authors proposed that a multiple-level strategy to assist protection selectivity could be used. These levels include protection based on local measurements; fast communications between adjacent relays in a type of logic selectivity scheme; and a supervisory level that operates on a longer timescale to update protection time grading settings to those appropriate for the current, and likely future, system conditions, incase the logic selectivity fails. The objective is to maintain as much selectivity as possible during network reconfigurations or temporary communication outages.

It is a likely scenario that an island will be formed by the clearing of a fault. However, this is a situation where island stabilization may be more difficult, as DG can move out-ofphase during the fault and on fault clearing will need to pull into synchronism. This means DG will need fault ride-through capability, so that generator protection does not operate before the fault has a chance to clear. During major faults, DG may need to be isolated from all loads. This would be followed by restoring the downstream side of the distribution network by merging islanded areas together.

The earthing arrangement must allow the island to remain earthed at all times. Solutions include connecting the star point of the generator to earth or switching in an earthing transformer once loss-of-mains is detected [33], or to use neutral voltage displacement to detect earth faults [34].

Automatic re-close has the benefit that temporary faults will only cause short interruptions. However, this technique may not be so important when islanding is used. As previously mentioned, automatic re-close time scales do need to be extended, or removed, when synchronous islanding is a possibility.

Fuses are solely a simple overcurrent device, and may have to be phased out as primary protection in distribution networks capable of islanding.

\section{Communications Requirement and Availability}

Observing the current roll-out of communications technologies would indicate that increased availability and reliability of broadband communications throughout the distribution network is inevitable, whether this is directly a result of Smart Grid applications or other consumer markets. Thus the required communications for power system islanding will become available independently to many, if not all, DG sites, and thus not be a financial barrier to islanding.

The communications network must be capable of transmitting a significant amount of data, some of which will be time critical. Control systems can be designed to be as resilient as possible to packet loss and latency.

Security is an issue being dealt with for a magnitude of applications [35]. As communications is deemed secure enough for many sensitive applications, then this is also true for power system islanding.

For long-term islanding to be possible, a high reliability of communications is a necessity. Naturally, the fall back during a communications outage is to disconnect DG and form smaller conventionally operated and protected islands. It is envisaged that with correct attention, communications will indeed be suitably reliable, but must still operate even when the power system is in crisis.

\section{CONCLUSION}

An island management scheme suitable for synchronous islands has been proposed. By endeavoring to have undefined islanding locations, this system can reduce the chance of load being unnecessarily excluded from the island, and permits maximum flexibility to be attained by the islanded system. The scheme will be enabled by communication links and a supervisory controller.

However, the necessary detection of island transitions may not be straight forward in a system held in synchronism with the utility by appropriate control. Thus, suitable methods of detection have been introduced and illustrated by Mathworks SimPowerSystems simulation. These include detecting island- 
ing, detecting island fragmentation, and identifying the DG in each island by monitoring the voltage phase difference between each pair of units, and between individual units and the utility.

Island merging and return-to-mains can be detected by monitoring the variance of voltage phase angle. A low variance can be assumed as equivalent to electrical connection. These transitions were difficult to detect in simulation without a varying load in the islanded system, however, a voltage phase angle variance method would be more discriminating on actual plant.

Accurate load sharing was shown to be achievable during synchronous islanded operation when a supervisory controller is employed. A load sharing scheme was implemented that introduces minimal phase difference error during the load sharing process. The scheme can also eliminate the control conflicts that affect multiple-set phase difference control. Multiple-set phase difference control is beneficial due to its fast response to disturbances and for the continuation of synchronous island control following the loss of a generator.

As islands will likely contain a considerable proportion of renewables which have variable power outputs, the control system must be able to cope with the fluctuation of power. The simulation indicates that appropriate control of the DG in the island can provide stable phase control with the power variations caused by a significant penetration of wind generation. Additional phase control support for the island could be provided by other types of renewable technology, energy storage and load management. It is suggested that the communication links can also be used to facilitate an adaptive protection system for the island.

This paper has proposed island control techniques that will be useful as part of future Smart Grids. The benefits of widescale power system islanding are matched by a high level of interest in the area. This field of work covers a substantial range of power system related disciplines with many challenges to be addressed. The adoption of new technologies by the distribution power system, such as broadband communications, will be a major step in achieving this. The authors look forward to continuing to work in this exciting area.

\section{APPENDIX}

The parameters for the synchronous machine of the gas turbine [36] and diesel generator [37] are in Table I, along with the governor parameters, and the exciter parameters, which are represented by the IEEE AC5A model [38]. Induction generator parameters are provided in Table II [39], and transformer parameters are given in Table III. All $11 \mathrm{kV}$ lines have an impedance of $0.33+\mathrm{j} 0.19 \Omega$.
TABLE I

SYNCHRONOUS MACHINE, GOVERNOR AND EXCITER PARAMETERS

\begin{tabular}{|c|c|c|c|c|c|}
\hline \multicolumn{3}{|c|}{ Component Description } & Unit & $\begin{array}{c}\text { Gas } \\
\text { Turbine }\end{array}$ & Diesel \\
\hline \multicolumn{3}{|c|}{ Synchronous machine parameters } & & & \\
\hline \multicolumn{2}{|c|}{ Power rating (nominal p.f. $=0.8$ ) } & & MVA & 4.5 & 2.0 \\
\hline \multicolumn{2}{|c|}{ Rated voltage } & & $\mathrm{kV}$ & 11.0 & 0.415 \\
\hline \multicolumn{2}{|c|}{ Inertia constant } & $\mathrm{H}$ & MWs/M & 1.05 & 1.48 \\
\hline \multicolumn{2}{|c|}{ Stator resistance } & $\mathrm{R}_{\mathrm{a}}$ & $\mathrm{pu}$ & 0.01 & 0.01 \\
\hline \multicolumn{2}{|c|}{ Direct axis sub transient reactance } & $X_{\mathrm{d} "}$ & pu & 0.17 & 0.15 \\
\hline \multicolumn{2}{|c|}{ Direct axis transient reactance } & $\mathrm{X}_{\mathrm{d}}$ & pu & 0.25 & 0.22 \\
\hline \multicolumn{2}{|c|}{ Direct axis synchronous reactance } & $X_{d}$ & pu & 2.95 & 2.65 \\
\hline \multicolumn{2}{|c|}{ Quadrature axis subtransient reactance } & $X_{\mathrm{q}}^{\prime \prime}$ & pu & 0.31 & 0.25 \\
\hline \multicolumn{2}{|c|}{ Quadrature axis synchronous reactance } & $\mathrm{X}_{\mathrm{q}}$ & pu & 1.35 & 2.0 \\
\hline \multicolumn{2}{|c|}{ Direct axis sub transient time constant } & $\mathrm{T}_{\mathrm{do} "}$ & $\mathrm{~s}$ & 0.055 & 0.03 \\
\hline \multicolumn{2}{|c|}{ Direct axis transient time constant } & $\mathrm{T}_{\mathrm{do}}$ & $\mathrm{s}$ & 5.5 & 3.5 \\
\hline \multicolumn{2}{|c|}{ Quadrature axis subtransient time constant } & $\mathrm{T}_{\mathrm{qo} "}$ & $\mathrm{~s}$ & 0.27 & 0.2 \\
\hline \multicolumn{2}{|c|}{ Armature leakage reactance } & $X_{a}$ & $\mathrm{pu}$ & 0.153 & 0.135 \\
\hline \multicolumn{6}{|c|}{ Governor Parameters } \\
\hline \multirow{4}{*}{$\begin{array}{l}\text { Prime } \\
\text { Mover }\end{array}$} & Time-constant & & $\mathrm{s}$ & 0.4 & 0.2 \\
\hline & Upper limit & & pu & 1.2 & 1.2 \\
\hline & Lower limit & & $\mathrm{pu}$ & -0.1 & -0.1 \\
\hline & Droop & $\mathrm{R}=1 / \mathrm{K}$ & $\mathrm{pu}$ & 0.05 & 0.05 \\
\hline \multirow{5}{*}{ PID } & Proportional gain & $\mathrm{K}_{\mathrm{p}}$ & & 11 & 18 \\
\hline & Integral gain & $\mathrm{K}_{\mathrm{i}}$ & & 9 & 24 \\
\hline & Derivative gain & $\mathrm{K}_{\mathrm{d}}$ & & 2.2 & 2.4 \\
\hline & Phase controller gain & & & 0.005 & 0.005 \\
\hline & Load share integrator gain & & & 0.1 & 0.1 \\
\hline \multicolumn{6}{|c|}{ Exciter Parameters } \\
\hline \multicolumn{2}{|c|}{ Regulator input filter time constant } & $\mathrm{T}_{\mathrm{r}}$ & $\mathrm{s}$ & 0.01 & 0.01 \\
\hline \multicolumn{2}{|c|}{ Regulator gain } & $\mathrm{K}_{\mathrm{a}}$ & pu & 400 & 500 \\
\hline \multicolumn{2}{|c|}{ Regulator time constant } & $\mathrm{T}_{\mathrm{a}}$ & s & 0.02 & 0.01 \\
\hline \multicolumn{2}{|c|}{ Maximum regulator output } & $\mathrm{V}_{\mathrm{Rmax}}$ & pu & 7.3 & 13 \\
\hline \multicolumn{2}{|c|}{ Minimum regulator output } & $\mathrm{V}_{\mathrm{Rmin}}$ & pu & -7.3 & -13 \\
\hline \multicolumn{2}{|c|}{ Exciter time constant } & $\mathrm{T}_{\mathrm{E}}$ & $\mathrm{s}$ & 0.55 & 0.35 \\
\hline \multicolumn{2}{|c|}{ Exciter constant } & $\mathrm{K}_{\mathrm{E}}$ & pu & 1 & 1 \\
\hline \multicolumn{2}{|c|}{ Feedback gain } & $\mathrm{K}_{\mathrm{f}}$ & pu & 0.03 & 0.03 \\
\hline Feedback & time constant & $\mathrm{T}_{\mathrm{f}}$ & $\mathrm{s}$ & 1 & 1 \\
\hline Exciter s & turation function parameter & $\mathrm{A}_{\text {sat }}$ & pu & 0.67049 & 0.21686 \\
\hline Exciter s & turation function parameter & $\mathrm{B}_{\text {sat }}$ & pu & 0.06479 & 0.48113 \\
\hline Load con & ipensation & $\mathrm{X}_{\mathrm{c}}$ & & 0.05 & 0.05 \\
\hline
\end{tabular}

TABLE II

INDUCTION GENERATOR PARAMETERS

\begin{tabular}{l|c|c}
\hline \multicolumn{1}{c|}{ Component Description } & Unit & Value \\
\hline Nominal voltage & $\mathrm{kV}$ & 0.69 \\
Rated output (p.f. =0.9) & $\mathrm{kW}$ & 500 \\
Stator resistance & $\mathrm{pu}$ & 0.0067685 \\
Cage resistance & $\mathrm{pu}$ & 0.0063 \\
Stator leakage reactance & $\mathrm{pu}$ & 0.08212 \\
Mutual unsaturated reactance & $\mathrm{pu}$ & 0.09642 \\
Rotor mutual reactance & $\mathrm{pu}$ & 3.6296 \\
Pole pair & & 2 \\
Inertia & $\mathrm{kgm}^{2}$ & 130 \\
\hline
\end{tabular}

TABLE III

TRANSFORMER PARAMETERS

\begin{tabular}{c|c|c|c}
\hline Voltage Ratio (kV) & $\mathbf{R}(\mathbf{p u})$ & $\mathbf{X}(\mathbf{p u})$ & Base (MVA) \\
\hline $33 / 11$ & 0.005 & 0.06 & 20 \\
$11 / 0.69$ & 0.01 & 0.05 & 6 \\
$11 / 0.415$ & 0.01 & 0.05 & 3 \\
\hline
\end{tabular}

\section{REFERENCES}

[1] N. Jenkins, R. Allan, P. Crossley, D. Kirschen, G. Strbac, Embedded generation, IEE Power and Energy Series 31, London, UK: The Institution of Electrical Engineers, 2000

[2] D. J. McGowan, D. J. Morrow, M. McArdle, "A digital PID speed controller for a diesel generating set", IEEE Power Eng. Soc. Summer Meeting, Toronto, Canada, vol. 3, pp. 1477 - 1482, Jul. 2003 
[3] M. Shahidehpour, Y. Wang, Communication and control in electric power systems - applications of parallel and distributed processing, Hoboken: John Wiley \& Sons, Inc. - IEEE Press, 2003

[4] T. S. Sidhu, E. Demeter, S. O. Faried, "Power system protection and control integration over ethernet-based communication channels", $\mathrm{Ca}$ nadian Conf. Elect. and Comput. Eng., Niagara Falls, Canada, vol. 1, pp. 225 - 228, May 2004

[5] N. Hatziargyriou, H. Asano, R. Iravani, C. Marnay, "Microgrids: an overview of ongoing research, development and demonstration projects”, IEEE Power \& Energy Mag., vol. 5, no. 4, pp. 78 - 94, Jul.-Aug. 2007

[6] P. Lund, "The Danish cell project - part 1: background and general approach', IEEE Power Eng. Soc. General Meeting, Tampa Bay, USA, pp. 1 -6, Jun. 2007

[7] IEEE Draft Guide for Design, Operation and Integration of Distributed Resource Island Systems with Electric Power Systems, IEEE P1547.4

[8] R. J. Best, D. J. Morrow, D. J. McGowan, P. A. Crossley, "Synchronous islanded operation of a diesel generator", IEEE Trans. Power Syst., vol. 22, no. 4, pp. 2170 - 2176, Nov. 2007

[9] R. J. Best, D. J. Morrow, D. M. Laverty, P. A. Crossley, "Synchrophasor broadcast over internet protocol for distributed generator synchronization”, IEEE Trans. Power Deliv., vol. 25, no. 4, pp. 2835-2841, Oct. 2010

[10] R. J. Best, D. J. Morrow, P. A. Crossley, "Effect of loading, voltage difference and phase angle on the synchronisation of a small alternator", IET Electric Power Applications, vol. 3, no. 6, pp. 531-542, Nov. 2009

[11] IEEE standard for interconnecting distributed resources with electric power systems, IEEE Std 1547-2003, Jul. 2003

[12] Electricity Association: Engineering Technical Report (ETR) No. 113: Notes of guidance for the protection of embedded generating plant up to $5 \mathrm{MW}$ for operation in parallel with public electricity suppliers' distribution system, UK, 1995

[13] R. Best, D. J. Morrow, D. Laverty, P. Crossley, "Universal application of synchronous islanded operation", CIRED seminar SmartGrids for Distribution, pp. 1 - 4, Jun. 2008

[14] K. Sun, D.-Z. Zheng, Q. Lu, "Searching for feasible splitting strategies of controlled system islanding', IEE Proc.: Gener. Transm. Distrib., vol. 153, no. 1, pp. 89 -98, Jan. 2006

[15] R. Caldon, A. Stocco, R. Turri, R. "Adaptive islanded configuration for quality improvement in power delivery systems with distributed generation", IEEE International Conference on Power Tech, St. Petersburg, Russia, Jun. 2005

[16] H. You, V. Vittal, X. Wang, "Slow coherency-based islanding", IEEE Trans. Power Syst., vol. 19, no. 1, pp. 483-491, Feb. 2004

[17] R. H. Lasseter, P. Paigi, "Microgrid: a conceptual solution", IEEE 34th Annual Power Electronics Specialists Conference (PESC), vol. 6, pp. 4285-4290, Jun. 2004

[18] J. A. P. Lopes, C. L. Moreira, A. G. Madureira, "Defining control strategies for microgrids islanded operation", IEEE Trans. Power Syst., vol. 21, no. 2, pp. 916-924, May 2006

[19] R. J. Best, D. J. Morrow, C. F. Ten, D. M. Laverty, P. A. Crossley, "Management of a multiple-set synchronous island", IEEE PES General Meeting, July 2009, Calgary, Canada, pp. 1-6

[20] IEEE standard for synchrophasors for power systems, IEEE Std. C37.118-2005, Mar. 2006

[21] D. M. Laverty， D. J. Morrow， R. J. Best， P. A. Crossley，"Differential ROCOF relay for loss-of-mains protection of renewable generation using phasor measurement over internet protocol" CIGRE/IEEE Joint Symposium, Calgary, Canada, pp. 1-7, Jul. 2009

[22] L.L.J. Mahon, 1992, Diesel Generator Handbook, Butterworth Heinemann, Oxford, UK, 1992

[23] D. J. McGowan, D. J. Morrow, B. Fox, "Multiple input governor control for a diesel generating set", IEEE Trans. Energy Convers., vol. 23, no. 3, pp 851- 859, Sep. 2008

[24] M. N. Marwali, J. W. Jung, A. Keyhani, "Control of distribution generation systems - Part II: load sharing control", IEEE Trans. Power Electr., November 2004, vol. 19, no. 6, pp. 1551-1561, Nov. 2004

[25] K. Tomsovic, D. Bakken, V. Venkatasubramanian, A. Bose, "designing the next generation of real-time control, communication, and computations for large power systems", Proc. IEEE, Energy Infrastructure Defence Systems, vol. 93, no. 5, pp. 965-979, 2005

[26] IEEE guide for automatic reclosing of line circuit breakers for ac distribution and transmission lines, IEEE Std C37.104-2002, Sep. 2002
[27] P. Lundsager, H. Binder, N.-E. Clausen, S. Frandsen, L. H. Hansen, J. C. Hansen, "Isolated systems with wind power - main report", RisoR-1256(EN), Riso National Laboratory, Roskilde, Denmark, Jun. 2001

[28] M. Shahabi, M. R. Haghifam, M. Mohamadian, S. A. Nabavi-Niaki, "Microgrid dynamic performance improvement using a doubly fed induction wind generator", IEEE Trans. Energy Convers., vol. 24, no. 1, pp. 137-145, Mar. 2009

[29] F. A. Bhuiyan, A. Yazdani, "Multimode control of a DFIG-based wind power unit for remote applications", IEEE Trans. Power Del., vol. 24, no. 4, pp. 2078-2089, Oct. 2009

[30] R. J. Best, C. F. Ten, D. J. Morrow, P. A. Crossley, "Synchronous island control with significant contribution from wind power generation", CIGRE/IEEE Joint Symposium, Calgary, Canada, pp. 1-6, Jul. 2009

[31] J. L. Blackburn, T. J. Domin, Protective relaying principles and applications, CRC press, Taylor and Francis Group, Boca Raton, $3^{\text {rd }}$ ed. 2007.

[32] R. J. Best, D. J. Morrow, P. A. Crossley, "Communication assisted protection selectivity for reconfigurable and islanded power networks", UPEC, Glasgow, Scotland, pp. 1-5, Sep. 2009

[33] DTI, "Islanded operation of distribution networks", Econnect, 2005, (available at: http://www.ensg.gov.uk/assets/dgcg00026.pdf, accessed Jan. 2010)

[34] DTI, "Assessment of islanded operation of distribution networks and measures for protection", Econnect, 2001, (available at: http://www.berr.gov.uk/files/file15099.pdf, accessed Jan. 2010)

[35] S. Ward, et al, C1 working group members of power system relaying committee: 'Cyber security issues for protective relays', IEEE Power Engineering Society General Meeting, , Tampa Bay, Florida, pp. 1-27, Jun. 2007

[36] Electricity Association "Engineering Technical Report No. 113: Notes of guidance for the protection of embedded generating plant up to 5 MW for operation in parallel with electricity suppliers' distribution systems" (UK, 1995)

[37] http://www.ipsa-power.com

[38] IEEE recommended practice for excitation system models for power system stability studies, IEEE Std 421.5-2005

[39] Thirinnger, T.: 'Frequency scanning for power system property determination - applied to a wind power grid', IEEE Transactions on Power Systems, May 2006, vol. 21, no. 2, pp. 702-708

\section{BIOGRAPHIES}

Robert J. Best was born in Belfast, Northern Ireland, in 1980. He received the M.Eng. and Ph.D. degrees from Queen's University Belfast, Belfast, U.K.,

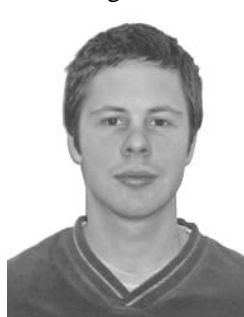
in 2004 and 2008, respectively.

He is currently a Research Fellow with the Electrical Power and Energy Research Cluster at Queen's University Belfast, with research interests in power system islanding, distributed generation and electric machinery.

Dr. Best is a member of the IET.

D. John Morrow (M'99) was born in Dungannon, Northern Ireland, in 1959. He received the B.Sc and Ph.D. degrees from Queen's University Belfast, Belfast, U.K., in 1982 and 1987, respectively.

$\mathrm{He}$ is a Reader in electrical engineering at Queen's University Belfast, Belfast, U.K., where he has been since 1987, with research and consulting interests in electric power systems, power system instrumentation, and control and protection of distributed generation.

Dr. Morrow is a member of the IET and also a member of the IEEE PES Excitation Systems Subcommittee. 


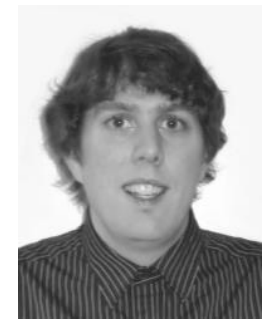

David M. Laverty (S'07) was born in Belfast, Northern Ireland, in 1984. He received the M.Eng and $\mathrm{Ph} . \mathrm{D}$. degrees from Queen's University Belfast, Belfast, UK, in 2006 and 2010 respectively.

Since graduating he has been with the Electrical Power and Energy Research Cluster at Queen's University Belfast, Belfast, UK. His placements as an undergraduate were with Northern Ireland Electricity and Universität Paderborn, Germany. His current research interests are in power system measurements, anti-islanding detection, phasor measurements, and Smart Grid telecommunications, messaging and security.

Dr. Laverty is a member of and volunteer with the IET.

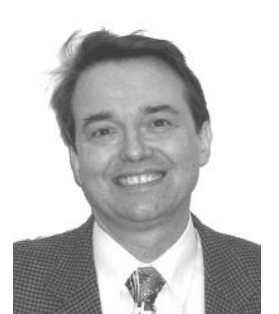

Peter A. Crossley (M'95) was born in the U.K. in 1956. He received the B.Sc. degree from the University of Manchester (formerly UMIST), Manchester, U.K., in 1977 and the Ph.D. degree from the University of Cambridge, Cambridge, U.K., in 1983.

$\mathrm{He}$ is Director of the Joule Centre, Manchester, UK, and a Professor of Electrical Engineering at the University of Manchester. He has been involved in the design and application of protection systems for many years, with GEC, ALSTOM, Queen's University Belfast, and The University of Manchester. He has published numerous technical papers on power system protection, embedded generation, and condition monitoring.

Dr. Crossley is an active member of various CIGRE, IEEE, and IET committees on protection and control. 